REVISTA DE LA UNIVERSIDAD DEL AZUAY

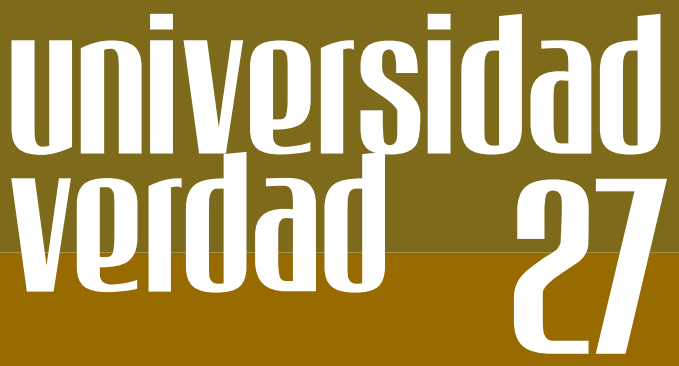

UNIVERSIDAD DEL AZUAY

\title{
GLOBALIZACION Y CULTURA: DEL HOGAR A LA CASA FETICHE EN LA ARQUITECTURA POPULAR AZUAYA
}

Diego Jaramillo

Presidente de la Casa de la Cultura Ecuatoriana

"Benjamín Carrión", Núcleo del Azuay 
El presente estudio pretende una primera aproximación al proceso de transformación de la arquitectura popular rural del Azuay, como consecuencia de la modernización contemporánea.

No aspiramos a tener una mirada global del proceso señalado sino acercarnos al mismo a través de casos puntuales observados en el espacio rural. Tampoco intentamos un conocimiento de los cambios radicales que están ocurriendo en la cultura y las prácticas de habitar en el medio rural. Sólo pretendemos evidenciar los nuevos espacios arquitectónicos que cada vez, con mayor fuerza, se imponen en el paisaje rural, transformándole radicalmente y modificando unos rasgos identitarios que tradicionalmente han caracterizado nuestro entorno.

Entendemos estas transformaciones, en el marco de la globalización y su relación con la cultura; y, más concretamente, como parte de la modernización de la urbanización que experimenta nuestra ciudad.

\section{GLOBALIZACION Y CULTURA}

Si bien la globalización es primero y ante todo un hecho económico que encuentra su espacio en la división técnica del trabajo y en el predominio del capital financiero, es finalmente un proceso que abarca, alterando, el conjunto de la cultura y que se expresa en nuevas maneras de expresar y sentir la pertenencia al territorio y vivir la identidad.

En este contexto, ya no es posible la idea de territorio como unidad; al contrario, él sintetiza una experiencia de desorden que imposibilita una mirada de conjunto y nos remite a las nuevas 
maneras de creación y apropiación del territorio asociadas a los cambios perceptivos producidos por las nuevas tecnologías de la comunicación, a la heterogeneidad simbólica resultante de la desterritorialización e internacionalización de los mundos simbólicos y al desplazamiento de fronteras entre lo local y lo global, las tradiciones y la modernidad.

La modernización de la urbanización en nuestros países latinoamericanos, como parte de la globalización respondería a tres tipos de procesos complementarios: las nuevas demandas sociales surgidas con los nuevos movimientos sociales; la cultura del consumo que transforma radicalmente las formas de comportamiento y estilos de vida, ya no como una imposición desde fuera, sino como una respuesta interna, desde el interior de nuestras culturas; y, las nuevas tecnologías comunicacionales que impulsan a nuestras sociedades a la apertura e interconexión, multiplican los flujos de información, y al mismo tiempo borran memorias. ${ }^{1}$

Una de las caras de esta modernización de la urbanización se presenta como la ruralización de las ciudades. Debido a los procesos migratorios campo-ciudad, la cultura de una buena parte de quienes habitan la ciudad se encuentra entre la cultura rural en la que ellos o sus antecesores nacieron y que, por las exigencias de la ciudad, se presenta ya fracturada; $y$, los modos de vida plenamente urbanos. De esta manera adquieren vigencia formas de supervivencia rural incorporadas a la modernidad urbana.

En el caso particular de Cuenca y su entorno rural, dados los particulares flujos migratorios campo ciudad, (flujos diarios o semanales, con retorno al campo) y fundamentalmente a la migración de campesinos al extranjero (Europa, EEUU), se puede señalar que aparece otra cara de la modernización mencionada: la urbanización del campo entendida, no en el sentido de los urbanistas como la dotación de servicios e infraestructura sino, en sentido cultural amplio. También los habitantes rurales se encuentran a medio camino entre la cultura rural a la que pertenecen a medias y la cultura urbana de la que forman parte ellos o sus familiares emigrantes. 
Cada vez más el mundo rural está habitado por ciudadanos reales 0 virtuales que configuran un mundo simbólico heterogéneo y desterritorializado en el cual se instauran prácticas, saberes, sensibilidades y gustos nuevos. ${ }^{2}$

Es en este contexto complejo y de límites difusos en el que se sitúan las transformaciones del espacio rural, particularmente de la vivienda popular.

Ahora bien, la mención a la arquitectura popular nos lleva a precisar el término cultura popular, dentro de la cual la arquitectura está inserta o de la cual es una expresión.

\section{CULTURA POPULAR}

$\mathrm{Si}$, como lo señalan varios autores, el término cultura es uno de los más esquivos e imprecisos, el de cultura popular lo es mucho más todavía, porque a la ambigüedad del primero se suma ahora igual condición para lo popular.Como señala Ticio Escobar ${ }^{3}$ para el caso del arte popular y que se puede ampliar para la cultura popular: la teoría se encuentra a medio camino entre la antropología, la sociología y la política; toma conceptos diversos sin poder todavía integrarlos en un área disciplinaria propia, por lo que el tema no tiene todavía respuestas claras. "La cuestión de qué es pueblo, de quiénes son pueblo es compleja porque el contenido de este término aparece simultáneamente recortado desde enfoques distintos. Por eso, unas veces se entiende por pueblo a la masa; otras, al conjunto de ciudadanos sujetos de derechos y obligaciones jurídicas, a una entidad metafísica ideal, a las mayorías demográficas, a las clases explotadas, al conjunto de los sectores subalternos, etcétera". ${ }^{4}$

Las versiones tradicionalmente difundidas de pueblo han sido: una, el concepto populista de éste, entendido como entidad ideal, sin referencia al conflicto y como contenido homogéneo de la Nación; $y$, otra que parte de las condiciones sociales de producción y lo define como el conjunto de clases y fracciones de clase explotadas. Sin 
embargo, como lo señala Escobar, esta concepción de lo popular a más de presentar problemas teóricos al mezclar categorías pertenecientes a ámbitos diferentes, deja de lado importantes grupos que, desde los últimos años, cobran cada vez mayor importancia, actúa al margen del campo de la producción económica y sus contradicciones con el sistema no son conflictos clasistas, sino se sitúan en demandas sectoriales (étnicas, ecológicas, sexuales, etc.).

A partir de estas reflexiones, Escobar caracteriza lo popular en un sentido más amplio, partiendo de las diferentes formas de subordinación de diversos sectores excluidos de una participación efectiva, bien sea en lo social, económico, político, o en lo cultura; y, cuyas prácticas ocurren al margen o en oposición a lo dominante. La caracterización señalada remite al concepto de hegemonía que, para el autor citado, es especialmente fructífero para definir lo subalterno popular en nuestros países y permite evadir las simplificaciones simplistas que oponen lo dominante y lo dominado de manera definitiva como si fueran dos extremos completos y cerrados en sí mismo. "Acción hegemónica -dice Portantiero- sería aquella constelación de prácticas políticas y culturales desplegadas por una clase fundamental, a través de la cual logra articular bajo su dirección a otros grupos sociales mediante la construcción de una voluntad colectiva que, sacrificándolos parcialmente, traduce sus intereses corporativos en universales". ${ }^{5}$

Dentro del ámbito cultural, en el polo hegemónico dominante se podrían distinguir la cultura oficial estatal, la oficial eclesiástica, la erudita local, la erudita internacional y la de las masas. La cultura popular se ubica, precisamente, frente al polo hegemónico.

Ubicada así: "la cultura popular comprende las prácticas y discursos simbólicos de los sectores subalternos; sectores a los que, por su participación desventajosa en el producto social o por su situación de marginamiento en el acceso al poder, no les conviene apoyar el sentido dominante de la cultura hegemónica y desarrollan o mantienen formas culturales distintas". ${ }^{6}$ 
La condición de subordinación y la presencia de formas propias de cada comunidad como respuestas a esa condición, son elementos esenciales para conceptualizar la cultura popular: Estas formas son propias o particulares de la comunidad en la medida que expresan el punto de vista interno de la comunidad; por lo tanto "para hablar de lo cultural popular, tienen que considerarse tanto las condiciones externas, la circunstancia de subordinación, como la misma autoconciencia de identidad colectiva, el reconocimiento de pertenencia a un grupo a una clase o comunidad y el sentirse parte de su experiencia y de su destino". 7 Por lo tanto para comprender el concepto de pueblo, en el marco de las prácticas culturales, es necesario situar a los sectores populares no sólo desde una condición objetiva de subordinación, sino, también, desde la perspectiva de cómo sienten su historia y se expresan a partir de ella; y, cómo desde allí se estructura su identidad social. En este sentido lo popular adquiere dimensión histórica concreta.

Por lo anotado, para caracterizar lo popular es indispensable la referencia a lo colectivo, a la solidaridad, a la cohesión de grupo y a la conciencia compartida, que constituyen elementos igualmente importantes como la dominación"y por eso es cultura popular el conjunto de prácticas de un grupo subalterno que se reconoce como comunidad particular y produce sus propios símbolos (o hace suyos símbolos ajenos) de acuerdo a sus necesidades colectivas. Estos símbolos se vuelven específicos del grupo y constituyen propuestas alternativas a las de la cultura dominante, ya sea que nieguen, incorporen, resistan 0 asimilen elementos de ella. ${ }^{8}$

\section{DEL HOGAR AL FETICHE DE LA CASA}

A dónde lleva este camino, preguntamos en Corpanche (Parroquia de Checa) a una vieja campesina: "arriba, abajo, al centro, a todas partes va este camino señor" fue su respuesta. Esta frase, en otro sentido, parece expresar las profundas transformaciones del medio rural, los desquiciamientos del entorno con una arquitectura que perdió su camino guía y que estéticamente se dispersa, pierde 
su sentido original de morada humana y adquiere otros nuevos vinculados al status.

En el marco rural de la modernización mencionada y sobre la base económica de las remesas de la emigración, ${ }^{9}$ el paisaje rural alrededor de Cuenca y en general la provincia, va cambiando rápida y bruscamente.

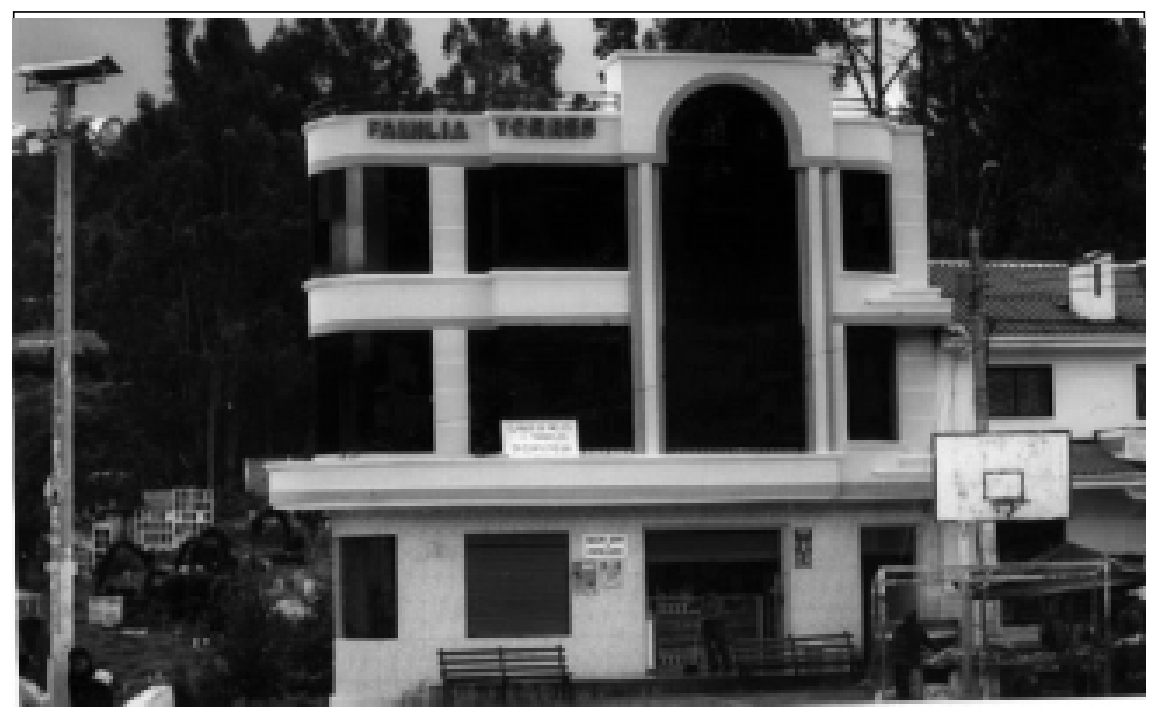

La arquitectura rural, hogar de la familia campesina y por tanto soporte y expresión material de una práctica de vida ligada al trabajo agrícola, la producción artesanal y unas relaciones sociales muy particulares, desaparece o pasa a un segundo plano en la valoración de la comunidad; $y$, es sustituida por una nueva arquitectura que responde a modos de vida urbanos y a una estética pobre, igualmente producida y consumida en la ciudad.

Aquella arquitectura de tierra, de adobe o tapial, de bahareque, de teja cerámica, de soportales y galerías de madera cada vez es más una excepción en nuestros campos y con su desaparición pasan 


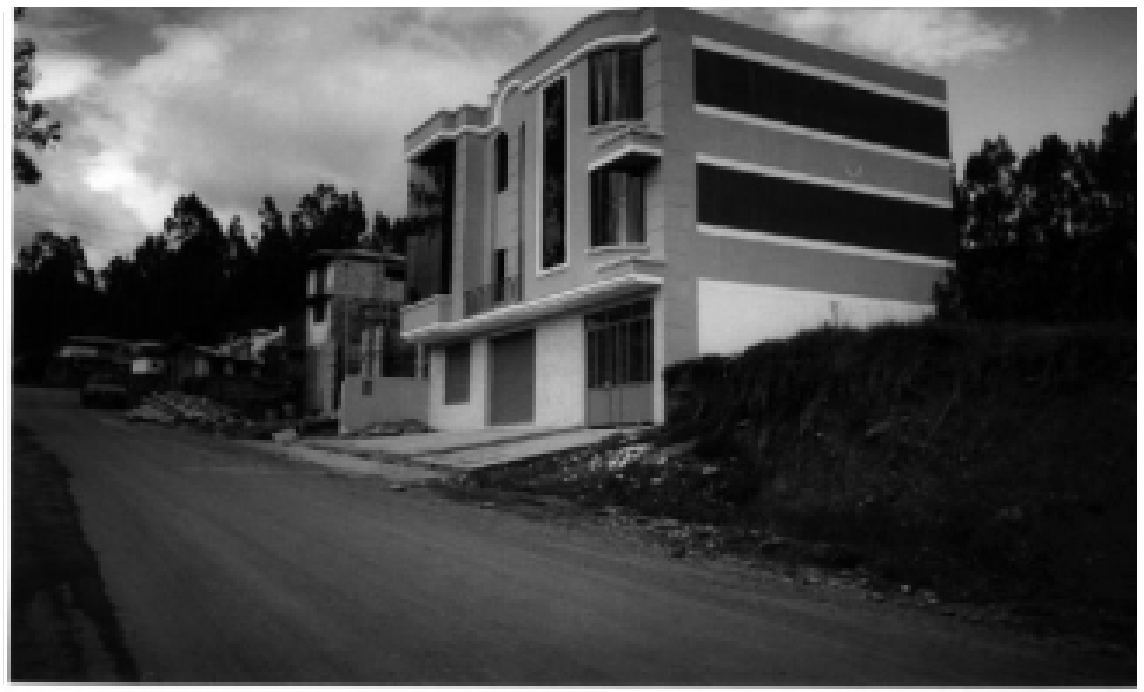

al olvido antiguos saberes tecnológicos, antiguas prácticas constructivas que se sustentaban en relaciones comunales de solidaridad social (la minga, el prestamanos). En su reemplazo están los "nuevos" materiales y técnicas: el bloque de cemento, el vidrio bronce, el hormigón, el aluminio, el gres, etc., "ordenados" bajo una estética del

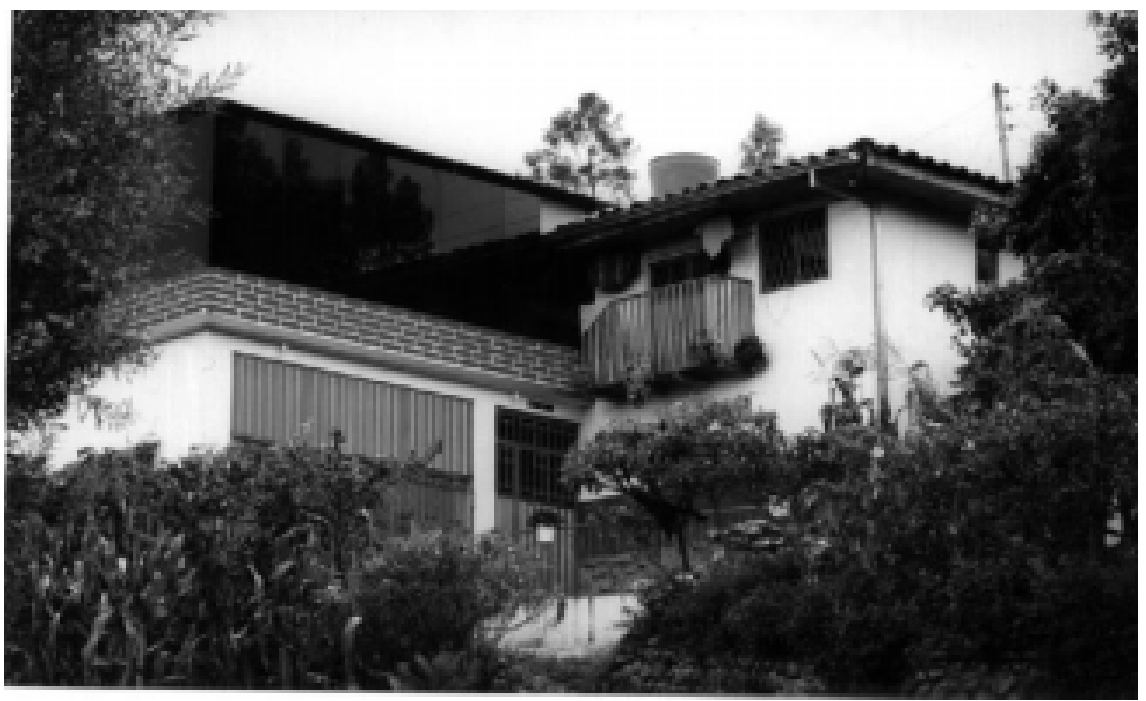


"rebusque" a manos de nuevos contratistas "especializados" y uno que otro arquitecto.

Aquella arquitectura "volcada hacia fuera", en la que básicamente el espacio interior cumplía la función de dormitorio y la actividades sociales de reunión y de trabajo artesanal se desarrollaban en el soportal y galería exterior, vinculadas a la naturaleza, el paisaje y a lo público, han cedido paso a una arquitectura "interiorista" encerrada en sí misma, reproduciendo prácticas típicamente urbanas. La gente ya no se reúne en el soportal a conversar, ahora se encierra a ver televisión. Al espacio social de participación e interrelación personal espontánea le ha ganado el VHS. Se esconden, se privatizan las prácticas. Se expone, se hace público el signo.

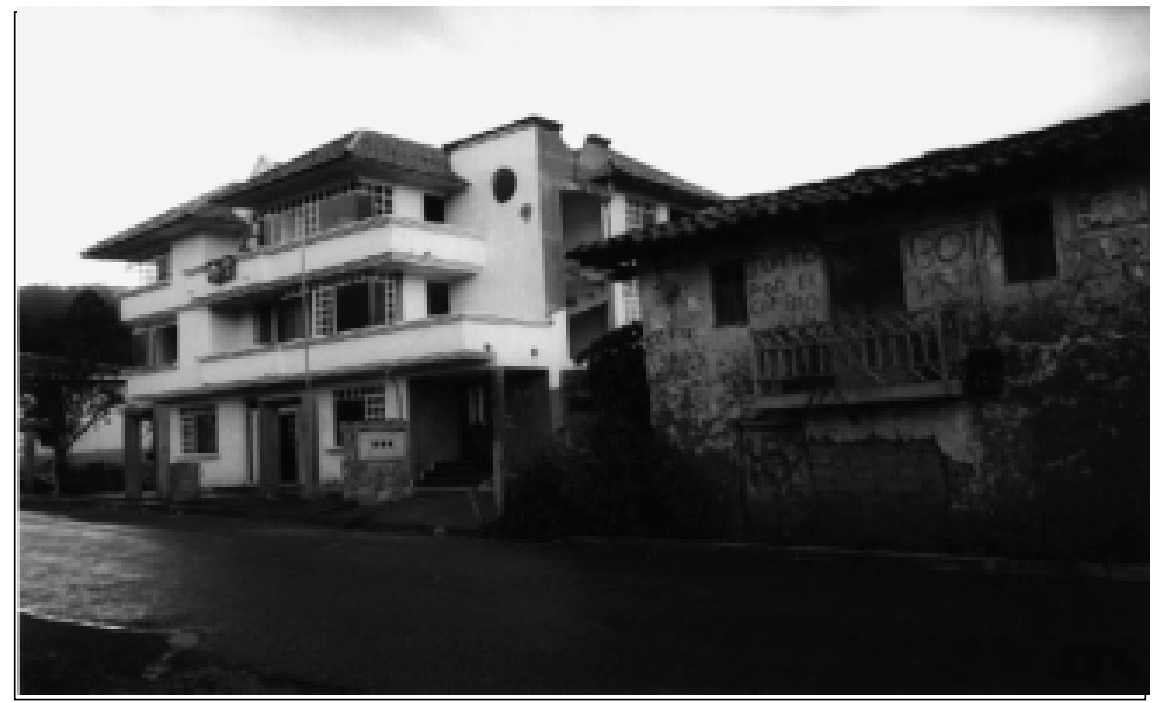

Obviamente los cambios en las prácticas de vida de una comunidad son procesos pausados y más lentos de lo que podría observarse en nuestro medio rural a través de su nueva arquitectura. Aquí parecería que los objetos se han adelantado a su contenido, que los signos se han vaciado de su significado original, para adquirir otro que se ha vuelto preponderante: el de status económico y prestigio social, el de que "me ha ido bien en la IONY". Así estamos en la 
transición de la arquitectura como morada, al fetiche de la casa. Del hogar, al letrero.

Esta situación podría estar reforzada por la condición de ausencia del jefe de familia y la permanencia de sus familiares en casas de parientes o amigos. Se observa entonces nuevas viviendas sin habitantes, no casas abandonadas (éstas son las antiguas casas tradicionales). Objetos precedentes a su contenido que potencian otros sentidos.

En otros casos la familia mezcla, superpone, funde y confunde viejas y nuevas prácticas y acopla y forza sus tradicionales formas de habitar a espacios extraños en un curioso y creativo collage de necesidades y funciones: los granos y las gallinas conviven sobre el auto del año en el garaje, o el auto con ellos en el gallinero. La terraza o el balcón (sustituto del portal y galería) con la ropa a secar. La sala también puede ser aula para clases de inglés a los vecinos, o centro de cómputo si fue eficaz el letrero que los anuncia.

De otra parte, a más de edificaciones nuevas, también ocurren las "mejoras" y ampliaciones de las existentes que más se producen para ser expuestas que por reales necesidades; estas mejoras abarcan, en algunos casos, a las casas de los padres del emigrante. Pues no está bien que éste habite en su vieja casa como signo del olvido al que le ha echado su hijo desde lejos. Es justo que ocupe un espacio de cristal desde el cual él ve que lo están viendo y por el cual, sobre todo, el hijo desde lejos, desde el extranjero, observa que le están viendo a él a través de su padre; y, entonces, se observa a sí mismo. ¡Casa espejo! En esos vidrios también se reflejan la condición, aspiraciones y sueños de los vecinos; y, entonces el emigrante se vuelve a ver, se reconoce por la situación de los otros.

El alegre grito de llamado del vecino se ha silenciado por un civilizado y educado "portero eléctrico", el señorial muro de piedras y pencos, por "cerramientos" de hierro, malla o piedra pintada; el nombre del vecino, conocido por todos en el pueblo, por un letrero que no vende otra cosa que prestigio. 
Así se va conformando un paisaje cultural a medio camino entre el mal gusto urbano y lo rural. Una especie de barrios urbanos en un medio rural o, dicho mejor, asentamientos rurales desanclados como expresión de una cultura desanclada, en la que surgen nuevas percepciones, códigos, sensibilidades, orientadas, en extremo, al reconocimiento social a través de una estética del prestigio y del individualismo.

Una nueva cultura que se constituye sobre la base de referentes urbanos y que es parte fundamental de la modernización de los procesos de urbanización que vive Cuenca; y, que al contrario de la cultura popular,ya no tiene sustento en lo colectivo, en la solidaridad, en la cohesión del grupo, sino por el contrario reproduce rasgos de la cultura hegemónica. Es de estos cambios que la nueva arquitectura rural es mediación: cambios que van produciendo que la cultura popular campesina se diluya y que sus actores, siguiendo el camino de Corpanche, vayan "arriba, abajo, al centro, a todas partes" y ocupen casas de cristal-espejo.

\section{NOTAS}

1. Al respecto ver: Martín Barbero, Jesús: "La ciudad virtual". Revista de la Universidad del Valle, Cali, Agosto 1996.

2. Según cifras oficiales y estimaciones hechas por el BID en América Latina y el Cribe, las remesas enviadas por los emigrantes a sus países de origen, sumaron en el año 2000 veinte millones de dólares. El Ecuador se ubica en quinto lugar de la lista de países que recibieron los mayores volúmenes de remesas, con 1.247 millones de dólares, que representa el $10 \%$ del $\mathrm{PIB}, 10$ veces el monto que recibe en asistencia para el desarrollo, 5 veces más que sus exportaciones de banano, el $84 \%$ de sus exportaciones petroleras. Diario El Mercurio, Cuenca, Ecuador, 16-05-2001, p. 8C. 
Según el Gerente del Banco Central, los principales rubros de ingresos de divisas en el año 2000 fueron petróleo 41\%, remesas de emigrantes $22 \%$, productos no tradicionales $18 \%$, banano $13 \%$, camarón $4 \%$, cacao y café $2 \%$. En los últimos tres años se estima que salieron alrededor de 243.000 ecuatorianos a trabajar en el exterior, es decir el $42.5 \%$ del total acumulado desde los años 80 y 90 que alcanza a las 550.000 personas. Los emigrantes corresponden al Azuay 47\%, Guayas 10\%, Pichincha 5\%, Manabí 5\%, Loja 4\%, Cañar 4\%, resto del país 25\%. Las remesas provienen principalmente de EEUU $45 \%$, España 30\%, Italia 10\%, Canadá 4\%, Australia 10\%,otros países $9 \%$. Diario El Mercurio,Cuenca, Ecuador, 23-05-2001, pág. 1a

3. Ver: Acha, Juan, Colombres, Adolfo, Escobar, Ticio: Hacia una teoría americana del arte, Ediciones del Sol, Buenos Aires, 1991, p. 91 y ss.

4. Ibid, p. 121.

5. Ibid, p. 128.

6. Ibid, p. 138.

7. Ibid, p. 139.

8. Ibid, p. 140.

9. Fundamentalmente, hasta ahora, ese dinero se ha orientado a la adquisición de bienes de consumo y confort y poco a inversiones productivas. Vivienda y automóviles han sido los bienes preferidos a tal punto en el caso de la vivienda, que el proceso ha sostenido una elevación del precio del suelo urbano y rural y del precio de construcción, sin precedentes en el medio y ha hecho de ellos, unos de los más altos del país.

\section{BIBLIOGRAFIA}

MARTÍN BARBERO, Jesús. "La ciudad virtual". Revista de la Universidad del Valle, Cali, Agosto 1996.

ACHA, Juan, Colombres, Adolfo, Escobar, Ticio. Hacia una teoría americana del arte. Ediciones del Sol. Buenos Aires, 1991.

MALO GONZÁLEZ, Claudio. Arte y Cultura Popular, Ed. Universidad del Azuay, Centro Interamericano de Artesanías y Artes Populares, Cuenca-Ecuador, 1996. 
